\title{
M2 Polarized Macrophages and Giant Cells Contribute to Myofibrosis in Neuromuscular Sarcoidosis
}

\author{
Stefan Prokop, ${ }^{*}$ Frank L. Heppner, ${ }^{*}$ \\ Hans H. Goebel, ${ }^{* \dagger}$ and Werner Stenzel ${ }^{\star}$ \\ From the Department of Neuropatbology, * Charite- \\ Universitätsmedizin Berlin, Berlin; and the Department of \\ Neuropathology, ${ }^{\dagger}$ University Medicine, Johannes Gutenberg \\ University, Mainz, Germany
}

The etiopathogenesis of sarcoidosis, a systemic granulomatous disease, still remains obscure. A multitude of organs have been described to be affected in systemic sarcoidosis. Skeletal muscles may also be affected, leading to myalgia and weakness. A workup of the specific immune response with emphasis on the macrophage response is provided herein. Affected muscle tissue from seven patients with systemic sarcoidosis was analyzed and compared with that from seven patients with other myopathies containing macrophagocytic infiltration. Monocytes/macrophages and giant cells in granulomas of muscle tissue from patients with sarcoidosis show a status of alternative activation (M2) based on their expression of CD206, CD301, arginase-1, and suppressor of cytokine signaling-1 as a consequence of a functionally type 2 helper $T$ cell (Th2)biased cytokine profile. Significant fibrosis and upregulation of CCL18 were associated with the M2 phenotype of macrophages. Conversely, up-regulated Th1 cytokines did not result in significant classical activation of macrophages (M1), with poor inducible nitric oxide synthase and cyclooxygenase-2 production. Giant cell formation was further associated with up-regulated expression of DNAXactivating protein of $12 \mathrm{kDa}$ (DAP12; gene symbol TYROBP). Functionally, alternative activation of macrophages on the basis of a Th2-biased immune response may induce clinical symptoms and chronic evolution of neuromuscular sarcoidosis. This is the first characterization of Th2-mediated immune mechanisms in neuromuscular sarcoidosis suggesting that a specific macrophage activation status leading to myofibrosis may be a key event in the pathogenesis of this disease. (Am J Pathol 2011, 178:1279-1286; DOI: 10.1016/j.ajpath.2010.11.065)
Sarcoidosis, an inflammatory immune-mediated systemic disease, primarily affects the lungs and the skin, leading to characteristic granulomatous nonnecrotizing lesions that can be easily diagnosed by means of light microscopic assessment (eg, of biopsy specimens). Sarcoidosis is detectable in any part of the nervous system and muscle. To establish a firm diagnosis of sarcoidosis, a comprehensive panel of diagnostic tests and a standardized workup of affected patients are proposed by the American Society of Rheumatology. ${ }^{1-3}$

From a purely descriptive standpoint, the lesions are classically viewed as nonnecrotizing epithelioid granulomas that contain mostly epithelioid cells/histiocytes and giant cells, surrounded by small round $\mathrm{CD}^{+}$and $\mathrm{CD}^{+} \mathrm{T}$ cells, B cells, and a few plasma cells. ${ }^{4-6}$ The immune response of patients with sarcoidosis has largely been considered to be type 1 helper $\mathrm{T}$ cell (Th1)-mediated based on the expression of Th1 cytokines such as IL-2, IL-6, IL-12, IL-18, tumor necrosis factor, interferon- $\gamma\left(\right.$ IFN- $\gamma$ ), and others. ${ }^{2,7-9}$ The development of granulomas in this context is thought to be the consequence of a chronic unknown stimulus, which is processed by macrophages, establishing the hypothesis of occult mycobacterial infection. ${ }^{10}$ However, theories on the etiology of sarcoidosis include a bacterial, a viral, and an autoimmune genesis. ${ }^{6,11-13}$ Sarcoidosis has also been described as an adverse secondary complication of medical treatment for hepatitis with ribavirin and/or IFN- $\alpha,{ }^{14,15}$ and other immunemodulating therapies. ${ }^{16}$ Skeletal muscle is involved in $5 \%$ to $50 \%$ of patients with generalized sarcoidosis, but isolated neuromuscular sarcoidosis can also occur in some instances. ${ }^{17}$

Besides the important role of $\mathrm{T}$ cells, macrophages and giant cells are major effector cells in sarcoidosis. ${ }^{18}$ Macrophages are prone to adjust their functional capacities according to their environment, in inflammatory and

Accepted for publication November 18, 2010.

Address reprint requests to Werner Stenzel, M.D., Department of Neuropathology, Charité-Universitätsmedizin Berlin, Charité Campus Mitte, Charitéplatz 1, Berlin D-10117 Germany. E-mail: werner.stenzel@ charite.de. 
Table 1. Clinical Findings in Seven Patients with Muscle Sarcoidosis

\begin{tabular}{ccccccc}
\hline $\begin{array}{c}\text { Patient } \\
\text { no. }\end{array}$ & $\begin{array}{c}\text { Age } \\
\text { (years) }\end{array}$ & Sex & $\begin{array}{c}\text { Duration of } \\
\text { disease }\end{array}$ & $\begin{array}{c}\text { Duration of } \\
\text { myopathy }\end{array}$ & Localization & $\begin{array}{c}\text { Corticosteroid } \\
\text { use }\end{array}$ \\
\hline 1 & 52 & $\mathrm{~F}$ & 5 months & 5 months & Proximal upper extremity & No \\
2 & 76 & $\mathrm{~F}$ & 26 years & 4 months & Proximal upper and lower extremities & Yes \\
3 & 68 & $\mathrm{~F}$ & NA & NA & NA & NA \\
4 & 75 & $\mathrm{~F}$ & 14 years & 1 months & Proximal upper extremity & No \\
5 & 74 & $\mathrm{~F}$ & 1 years & 1 years & Proximal upper extremity & Yes \\
6 & 78 & $\mathrm{~F}$ & 3 years & 1 years & Proximal lower extremity & No \\
7 & 69 & $\mathrm{M}$ & 1 years & 1 years & Proximal lower extremity & \\
\hline
\end{tabular}

F, female; M, male; NA, not available.

infectious contexts, and therefore macrophages are thought not to be terminally differentiated. ${ }^{19-23}$

\section{Materials and Methods}

\section{Patients and Biopsy Specimens}

Biopsied muscle tissue samples from seven patients with muscle sarcoidosis and seven patients with other diseases of the muscle that contain significant macrophage infiltrates [dermatomyositis $(n=2)$, Becker muscular dystrophy (BMD) $(n=2)$, necrotizing myopathy $(n=2)$, and macrophagic myofasciitis $(n=1)]$ were analyzed retrospectively. In each patient, sarcoidosis of the muscle was part of a generalized chronic sarcoidosis also involving the lungs. Available clinical information is given in Table 1. Informed consent was obtained from all the patients, and all the biopsy specimens had been cryopreserved at $-80^{\circ} \mathrm{C}$ before diagnostic workup.

\section{Histologic, Enzyme Histochemical, and Immunohistochemical Analyses}

Cryostat sections, $7 \mu \mathrm{m}$ thick, were stained with H\&E, Elastica van Gieson, modified Gömöri trichrome, and enzyme histochemically for nonspecific esterase and acid phosphatase. For immunohistochemical analysis, 7- $\mu \mathrm{m}$ thick cryostat sections were prepared for demonstration of CD3, CD4, CD8, CD11b, CD20, CD31, CD45/leuko- cyte common antigen, CD68, CD206/mannose receptor, CD301/macrophage galactose-type C lectin, fibrinogenic pulmonary and activation-regulated chemokine (CCL18), major histocompatibility complex (MHC) class I, MHC class II, and suppressor of cytokine signaling-1 (SOCS-1) (Table 2). Immunohistochemical analysis was performed using the NIEW-Ventana ABC Kit (Ventana, Illkirch, France), with appropriate biotinylated secondary antibodies and diaminobenzidine visualization of the peroxidase reaction product on a Benchmark XT immunostainer (Ventana). Omission of primary antibodies in control sections resulted in the absence of any cellular labeling.

\section{Quantitative Real-Time PCR}

Total RNA was extracted from all muscle tissue samples using the TRIzol/chloroform method according to the manufacturer's instructions (Invitrogen, Carlsbad, CA). Thereafter, RNA was resuspended in $60 \mu \mathrm{L}$ of diethylpyrocarbonate-treated water. Concentration of total RNA was determined using a fluorescence plate reader (Tecan Group Ltd, Männedorf, Switzerland). Owing to the uneven distribution of granulomas and of macrophage density in the investigated specimens, tissue that was collected for PCR analysis was reassessed histologically for the presence of the respective pathologic alterations in all investigated cases. The RNA was reverse transcribed using the High-Capacity cDNA Archive Kit (Applied Biosystems, Foster City, CA) according to the man-

Table 2. Source of Primary Antibodies Used for Immunohistochemical Studies

\begin{tabular}{lllll}
\hline \multicolumn{1}{c}{ Antibody } & \multicolumn{1}{c}{ Species } & \multicolumn{1}{c}{ Clone } & \multicolumn{1}{c}{ Company } \\
\hline CD3 & Monoclonal, mouse & PS1 & Novocastra & $1: 50$ \\
CD4 & Monoclonal, rabbit & SP35 & Zytomed & Undiluted \\
CD8 & Monoclonal, mouse & C8/144B & DAKO & $1: 100$ \\
CD11b & Monoclonal, mouse & SP2/0 & Novocastra & $1: 20$ \\
CD20 & Monoclonal, mouse & L26 & DAKO & $1: 400$ \\
CD31 & Monoclonal, mouse & JC70A & DAKO & $1: 400$ \\
CD45 & Monoclonal, mouse & 2B11 and PD7/26 & DAKO & $1: 10,000$ \\
CD68 & Monoclonal, mouse & KP1 & DAKO & $1: 100$ \\
CD206 & Monoclonal, mouse & 7-450 & Acris antibodies & $1: 200$ \\
CD301 & Monoclonal, mouse & 125A10.03 & Dendritics & $1: 100$ \\
CCL-18 & Polyclonal, rabbit & N/A & Lifespan Biosciences & $1: 1000$ \\
MHC class I & Monoclonal, mouse & W6/32 & DAKO & $1: 100$ \\
MHC class I & Monoclonal, mouse & CR3/43 & DAKO & $1: 100$ \\
SOCS-1 & Polyclonal, rabbit & N/A & Lifespan Biosciences & \\
\hline
\end{tabular}

N/A, not applicable. 

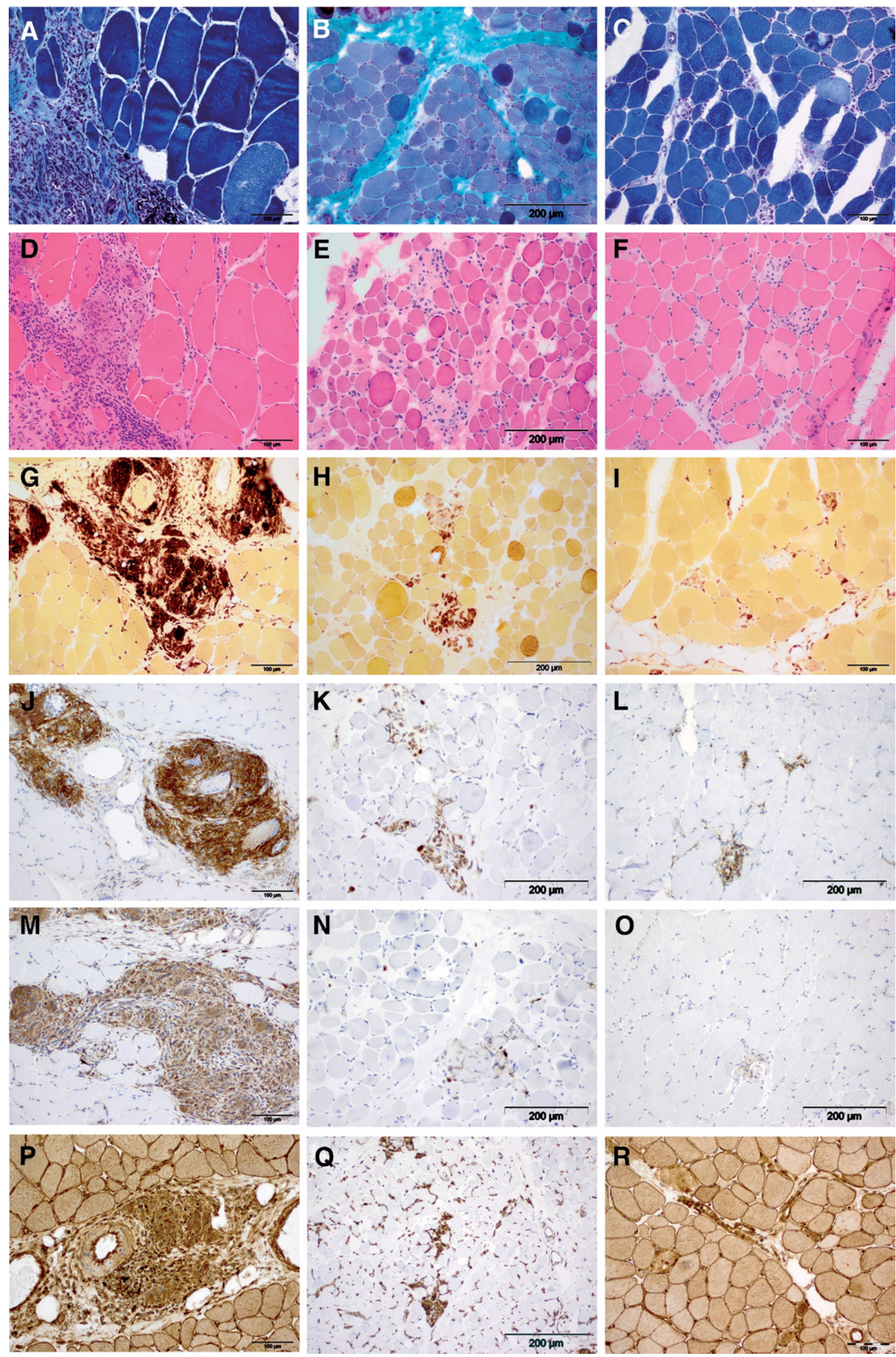

Figure 1. Macrophages, epithelioid cells, and giant cells in granulomas are illustrated by Gömöri stainings (A, B, and $\mathbf{C})$ and H\&E stainings $(\mathbf{D}, \mathbf{E}$, and $\mathbf{F})$ and nonspecific esterase preparation $(\mathbf{G}, \mathbf{H}$, and $\mathbf{I})$ in a patient with sarcoidosis $(\mathbf{A}, \mathbf{D}$, and $\mathbf{G})$ and in two control patients: BMD case $1(\mathbf{B}, \mathbf{E}$, and $\mathbf{H})$ and a patient with necrotizing myopathy $(\mathbf{C}, \mathbf{F}$, and $\mathbf{I})$. Monocytes strongly express CD68 (J, K, and $\mathbf{L})$, whereas CD11b is less intensely expressed in the control group ( $\mathbf{M}$ vs $\mathbf{N}$ and $\mathbf{O})$; MHC class 1 molecules $(\mathbf{P})$ are expressed on monocytes and additionally on the sarcolemma of muscle fibers of patients with muscle sarcoidosis and of those with necrotizing myopathy (P and $\mathbf{R}$ ), whereas in the BMD case, MHC class I molecules are expressed exclusively on monocytes $(\mathbf{Q})$. Original magnification, $\times 200$. 

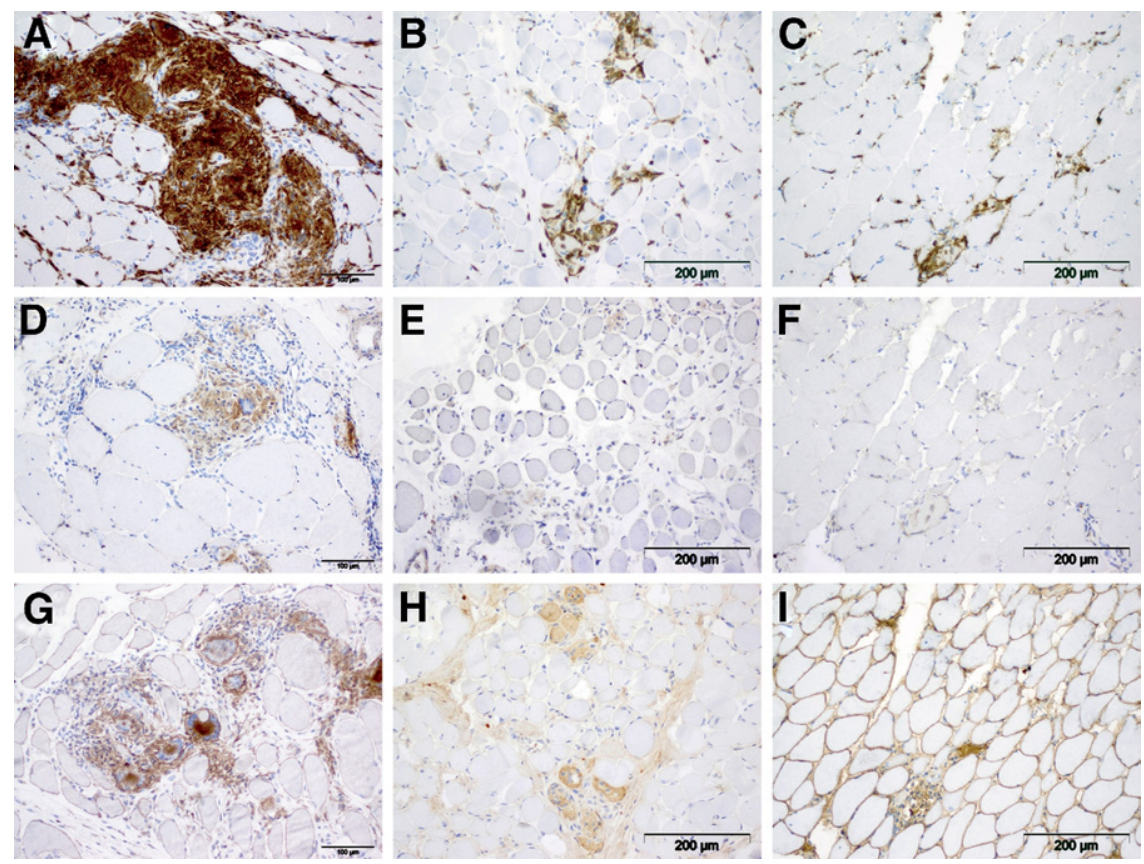

Figure 2. Macrophages/monocytes, giant cells and epithelioid cells strongly express the mannose receptor (CD206) (A), and they are also SOCS-1 positive (D). Focal up-regulation of CD206 was found on macrophages from the control group as illustrated: BMD case 1 (B) and necrotizing myopathy $(\mathbf{C})$. Macrophages from the control group, however, did not express SOCS-1 [BMD case 1 (E) and necrotizing myopathy $(\mathbf{F})$ ]. Immunohistochemical iNOS staining did not differ significantly in both groups as exemplified by iNOS staining of a muscle sarcoidosis specimen $(\mathbf{G})$ compared with a specimen from the patient with BMD (H) and from a patient with necrotizing myopathy (I). Original magnification, $\times 200$ ufacturer's protocol using $2 \mu \mathrm{g}$ of total RNA per sample as described previously. ${ }^{24}$

The expression levels of gene transcripts, and of the endogenous control gene, phosphoglycerate kinase 1 (PGK1), was analyzed in the specimens by means of quantitative real-time RT-PCR using the $5^{\prime}$-nuclease technology using an ABI PRISM 7900HT Sequence Detection System and the human TaqMan predeveloped assay reagents (Applied Biosystems). The assay identification numbers are as follows: IL-4, Hs00929862_m1; IL-4 receptor (IL-4R), Hs00166237_m1; IL-13, Hs99999038_m1; CD206, Hs00267207_m1; CD301, Hs00197107_m1; SOCS-1, Hs00705164_s1; CCL18, HS00268113_m1; arginase-1, Hs00968979_m1; DNAX-activating protein of $12 \mathrm{kDa}$ (DAP12; gene symbol TYROBP), Hs00182426_m1; inducible nitric oxide synthase (iNOS), Hs01075529_m1; IFN- $\gamma$, Hs00989291_m1; IL-18, Hs99999040_m1; IL27R, Hs00175472_m1; and PGK1, Hs99999906_m1.

The PCR reactions were prepared in a final volume of $20 \mu \mathrm{L}$ in the presence of the TaqMan Fast Universal PCR Master Mix (Applied Biosystems) containing a cDNA equivalent of $20 \mathrm{ng}$ of RNA. All analyses were performed in triplicate, and the threshold cycle was determined. Gene expression was concomitantly measured in normal muscle tissue as a calibrator to allow comparison between the different samples of muscle tissue containing sarcoidosis granulomas versus other muscle disease samples with inflammation using the $2\left(\Delta \Delta \mathrm{C}_{\mathrm{T}}\right)$ method. ${ }^{25}$

\section{Statistics}

The two-tailed $t$-test was applied for analysis of quantitative differences of mRNA transcripts. Data are presented as mean $\pm \mathrm{SD}$. The level of significance was set at $P<$ 0.05 .

\section{Results}

\section{Macrophages in Sarcoid Granulomas of Skeletal Muscle Exhibit the M2 Phenotype}

Granulomas of all the patients analyzed exhibited macrophages, epithelioid cells, and giant cells, with strong reactivity for nonspecific esterase. The presence of these myeloid cells was associated with severe myopathic changes in the muscle tissue and was found to be distributed throughout the endomysium and perimysium of the entire muscle specimen (Figure 1, A, D, and G). Immunohistochemical analyses consistently revealed the expression of CD68 (Figure 1J) and the pan-macrophage marker CD11b (Figure 1M) on macrophages, epithelioid cells, and giant cells. Although most macrophages were located in the granulomas, some macrophages were also found to be diffusely distributed in the endomysium. Upregulation of $\mathrm{MHC}$ class I molecules was detectable on macrophages, epithelioid cells, and giant cells and also on the sarcolemma of all muscle fibers (Figure 1P). All these monocytes strongly express the mannose receptor (CD206) (Figure 2A), and they are also SOCS-1 positive (Figure 2D), indicating an M2 phenotype of activation. No overt differences in the immunohistochemical expression of these markers were observed in the seven analyzed patients with sarcoidosis of the muscle, despite two of them undergoing corticosteroid treatment.

Macrophages from the control group (Figure 1, B, C, $\mathrm{E}, \mathrm{F}, \mathrm{H}$, and I) were also immunoreactive for CD68 (Figure 1, K and L) and poorly for CD11b (Figure 1, N and $\mathrm{O}$ ) and $\mathrm{MHC}$ class I (Figure 1, Q and R), whereas transsarcolemmal $\mathrm{MHC}$ class I expression on muscle fibers was not found in the BMD case (Figure 1Q). Most of the macrophages in the control groups exhibited varying $\mathrm{CD}_{206}{ }^{+}$staining intensities similar to muscular 
A
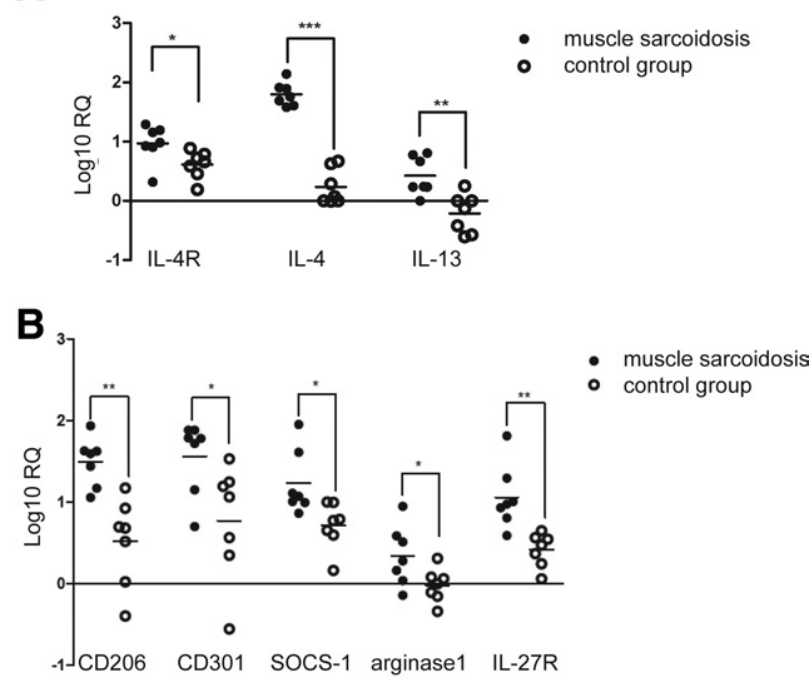

C

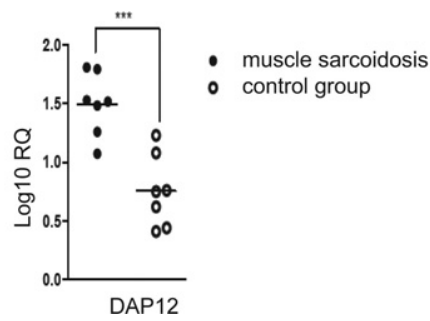

Figure 3. $\log _{10}$ Relative Quantification (RQ) values of mRNA calibrated against expression of the respective molecules in normal muscle specimens. A: Both of the experimental groups show expression of the common IL-4R, IL-4 is expressed significantly higher in the muscle sarcoidosis group, and IL-13 is exclusively expressed in that group. B: Markers of alternative activation are expressed at a significantly higher level. C: Furthermore, expression of DAP12 is also higher in the muscle sarcoidosis group. ${ }^{*} P<0.05,{ }^{* * *} P<0.01,{ }^{* * * * *} P<0.001$

dystrophy and necrotizing myopathy specimens (Figure 2, B and C), whereas SOCS-1 was absent or, if at all, hardly detectable compared with specimens derived from patients with sarcoidosis (Figure 2, E and $F$ ).

\section{Expression of Th2 Cytokines in Sarcoidosis Lesions of Skeletal Muscle Leads to Alternative Activation of Macrophages}

Presence of the common $\mathrm{IL}-4 \mathrm{R}$ is a prerequisite for effective (type 2 helper T cell Th2) signaling via the master cytokines IL-4 and IL-13. ${ }^{20}$ All specimens of the muscle sarcoidosis group showed robust expression of IL-4R, whereas IL-4R expression was significantly lower in the control group (Figure $3 \mathrm{~A}$ ). In line with this, IL-4 expression was significantly increased in the muscle sarcoidosis group, and IL-13 expression was restricted to specimens of the muscle sarcoidosis group (Figure 3A). Analyzing alternative activation markers of macrophages revealed that CD206, CD301, SOCS-1, and arginase-1 were significantly up-regulated in muscle biopsies of the muscle sarcoidosis group com- pared with the control group (Figure 3B). Furthermore, the IL-27R, which is expressed on IL-4- and IL-13primed M2 macrophages, ${ }^{26}$ was also significantly upregulated in this group compared with controls. In addition, DAP12, which regulates macrophage fusion in giant cell formation, ${ }^{27}$ was clearly up-regulated in the sarcoidosis group (Figure 3C).

\section{Expression of Th1 Cytokines in Sarcoidosis Lesions of Skeletal Muscle Resulting in Weak Classically Activated Macrophages}

Although the expression of IFN- $\gamma$ and IL-18, known to be essential for a functional Th1 response in pulmonary sarcoidosis, ${ }^{28}$ was found to be up-regulated in the muscle sarcoidosis group (Figure 4A), an anticipated subsequent up-regulation of iNOS and cyclooxygenase-2 was not detected (Figure 4B). Conversely, iNOS expression, indicating classical (M1) activation of macrophages, was found to be low on RNA levels in the muscle sarcoidosis group, whereas control specimens exhibited a somewhat more pronounced, however nonsignificant, expression (Figure 4B). Furthermore, iNOS staining was found in few macrophages and giant cells in granulomas of skeletal muscle sarcoidosis, indicating a certain degree of classical (M1) activation in the lesions (Figure 2G). Muscle specimens from the control group also showed iNOS immunoreactivity in the myophagocytes in BMD and necrotizing myopathy (Figure 2, H and I). In addition, IL-12p40 was highly expressed in the sarcoidosis group (Figure 4C), indicating a functional, but possibly disbalanced, IFN- $\gamma-$ $\mathrm{IL}-12$ axis in sarcoidosis of the muscle. Along these lines, the anti-inflammatory/regulatory cytokine IL-10 was expressed at significantly higher levels in the sarcoidosis group, lending further support for the M2 polarization of these macrophages (Figure 4C).

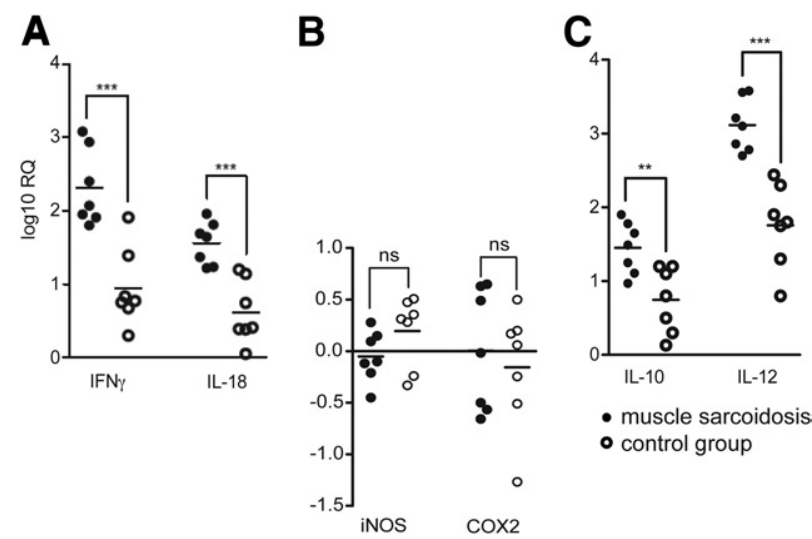

Figure 4. $\log _{10}$ values of mRNA calibrated against expression of the respec tive molecules in normal muscle specimens. Expression of IFN- $\gamma$ and IL-18 was significantly higher in the muscle sarcoidosis group than in the control group (A), whereas the expression of iNOS and cyclooxygenase-2 (COX2), as markers of classical macrophage activation, is not up-regulated in either groups (B). C: Expression of IL-10 and IL-12 was significantly higher in the muscle sarcoidosis group than in the control group. NS, not significant. ${ }^{* *} P<$ $0.01,{ }^{* * * *} P<0.001$. 

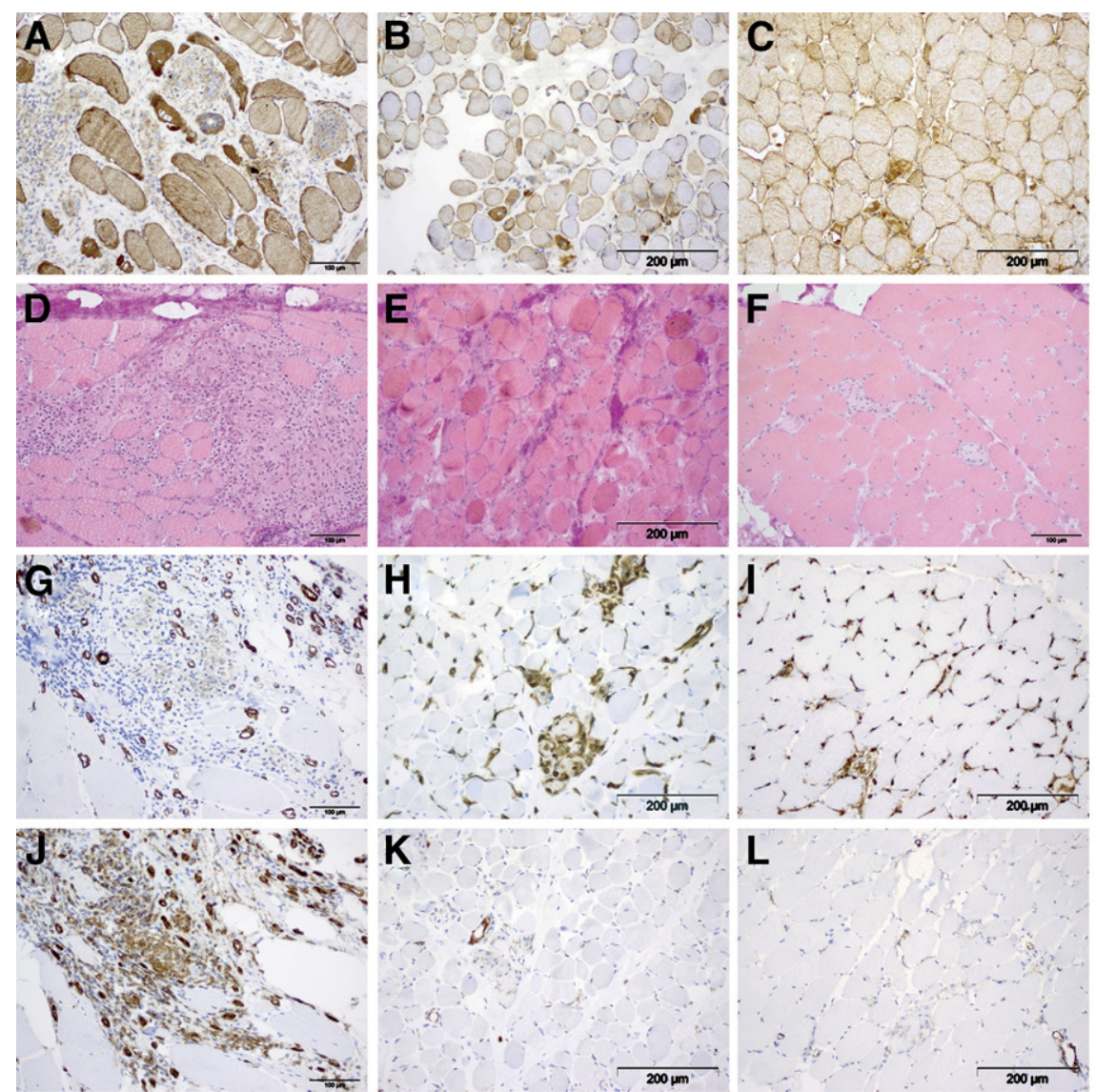

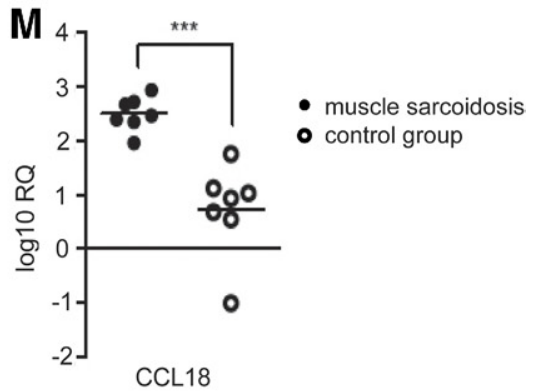

Figure 5. The chemokine CCL18 is expressed on the sarcolemma of muscle fibers but also in the granulomas (A); also, BMD and necrotizing myopathy muscle specimens showed immunoreactivity on their muscle fibers (B and $\mathbf{C}$ ). Endomysial and perimysial fibrosis is illustrated by means of elastica van Gieson staining in the sarcoidosis muscle (D). As expected, the BMD muscle (E), but not the necrotizing myopathy muscle (F), shows important fibrosis. Neovascularization is illustrated by the presence of CD31- (G) and smooth muscle actin(J) expressing vessels, whereas no neovascularization is detectable in the control specimens $(\mathbf{H}, \mathbf{I}, \mathbf{K}$, and $\mathbf{L}$ ). Original magnification, $\times 200$. M: Up-regulation of CCL18 can also be demonstrated at the mRNA level $\left(\log _{10}\right.$ values of mRNA calibrated against the expression of CCL18 in normal muscle specimens are illustrated). ${ }^{* * * * *} P<0.001$
These results indicate that Th2 activation via IL-4 and $\mathrm{IL}-13$ in muscle sarcoidosis is more important and effective than is Th1-mediated activation via IL-18 and IFN- $\gamma$, which results in an $\mathrm{M} 2$ rather than an $\mathrm{M} 1$ polarization of inflammatory macrophages.

\section{Alternative Activation of Macrophages Induces Myofibrosis in Muscle Sarcoidosis}

Expression of CCL18, an important chemokine involved in fibrosis in the lung, ${ }^{29}$ was significantly up-regulated in the muscle sarcoidosis group at the protein (Figure 5, A vs $B$ and $C$ ) and mRNA (Figure $5 \mathrm{M}$ ) levels. In line with this observation, severe endomysial and perimysial fibrosis in the muscle tissue from patients with sarcoidosis was visualized by elastica van Gieson staining (Figure 5, D vs E and F). Furthermore, neovascularization, as illustrated by immunohistochemical stainings for CD1 (Figure 5G) and smooth muscle actin (Figure 5J), was detectable in granulomas of patients with muscle sarcoidosis. Fibrous tissue was associated with CCL18 expression, which, although at significantly lower levels, was also evident in control specimens (Figure 5M). Fibrosis as detected in this specimen (Figure 5, B and E) is a well-known phenomenon in patients with BMD. However, these specimens and all other control muscles with even less fibrosis lacked cell-rich granulomas or neovascularization (Figure $5, \mathrm{H}, \mathrm{I}, \mathrm{K}$, and L). These data illustrate an essential chronic granulomatous tissue reaction in the sarcoidosis muscle specimens, which is localized to the macrophage/giant cell infiltrates.

\section{Discussion}

According to the generally accepted concept, sarcoidosis is thought to be a Th1-mediated disease. 2,8,9,30-33 Because sarcoidosis is a chronic disease in approximately $20 \%$ of patients, ${ }^{32}$ severe tissue damage and active repair mechanisms are evolving throughout the course of the disease. Herein, we show via analysis of macrophage function, and expression of their marker profiles in light of Th1 and Th2 activation, that macrophages and giant cells strongly express markers of alternative activation in muscle sarcoidosis. Furthermore, despite a strong Th1 stimulus, iNOS and cyclooxygenase-2 production as key mediators of classical activation of macrophages are only weakly expressed, whereas severe myofibrosis, clinically linked to muscle weakness and myalgia, is associated with $\mathrm{M} 2$ macrophages. Because of the dominant Th2 response, we conclude that M2-mediated chronic macrophage activity in concert with associated DAP12-induced giant cell formation is the basis for adverse and chronic evolution of the disease in the affected skeletal muscle.

In pulmonary sarcoidosis, a Th1-mediated immune response is documented by the presence of CD4 ${ }^{+} \mathrm{T}$ cells producing high levels of IFN- $\gamma, \mathrm{IL}-12, \mathrm{IL}-2,{ }^{30}$ and other Th1 cytokines, which are considered the main immuno- 
logic drivers in granuloma formation. ${ }^{31,33,34}$ The Th2 cells are thought to be inactive in such granulomas, also because low levels of the Th2-associated cytokines IL-4 and IL-13 were described. Because some patients develop sarcoidosis during treatment with IFN- $\alpha$ (mainly due to hepatitis $\mathrm{C}$ ), it has been argued that this may be due to exacerbation of a Th1-mediated immune response. ${ }^{35-38}$ The concept of an imbalanced immune response implicates that in the chronic disease course of sarcoidosis, there may be a shift toward increased Th2-type cytokines. However, Möllers et $\mathrm{al}^{39}$ found fewer Th2 cytokines in the alveolar compartment compared with in the peripheral blood. The Th2 cytokines may be of clinical relevance, especially in patients who develop lung fibrosis, ${ }^{40}$ given that increased IL-13 expression was described in bronchoalveolar lavage cells of patients with sarcoidosis. ${ }^{41}$ Because, to our knowledge, no studies on Th1/ Th2 immunopathogenesis in muscle sarcoidosis have been reported, the present findings, apart from explaining the pathogenesis of the morphologically typical lesions in the muscle, may also give insights into the principal pathogenetic stages of sarcoidosis, which also may apply to sarcoidosis lesions (eg, in the lungs or other tissues).

In muscle specimens from patients with sarcoidosis, macrophages with an M2 phenotype are by far the most abundant cell population. These M2 macrophages represent an alternative status of activation beside classical M1 activation, which is required for acute killing of microbial products via production of nitric oxide and oxygenfree radicals. ${ }^{20}$ Both iNOS and arginase- 1 share arginine as a substrate, and expression of either molecule is crucial for the functional properties of these macrophages and the ensuing immunopathologic condition. Because iNOS expression was absent in fibrotic parts of pulmonary lesions but was found to be increased in areas with strong inflammation, one can conclude that either fibrosis in muscle sarcoidosis is a more prominent feature or muscle involvement reflects a more chronic and stable stage of sarcoidosis. Because arginase-1, in contrast to iNOS, is known to induce collagen production via the production of prolines and the reconstruction of damaged extracellular matrix, accompanied by a switch of macrophages to an M2 "repair" phenotype, ${ }^{42,43}$ the herein reported significant arginase-1 expression and clear M2 marker profile with high levels of CD206 and CD301 on macrophages and giant cells in muscle specimens from patients with sarcoidosis are striking.

CD206 $^{+}$macrophages have only recently been described in the context of muscle diseases (Duchenne muscular dystrophy) by Desguerre et al, ${ }^{44}$ and the relevance of these cells in myofibrosis has been pointed out. However, we did not detect any increased angiogenesis in our dystrophy patients' specimens. Conversely, important neovascularization in the granulomas and the adjacent inflammatory muscle tissues may also be the consequence of a sustained IL-4 effect on macrophage activity. ${ }^{45,46}$ We identified a significant up-regulation of SOCS- 1 in the muscle of patients with sarcoidosis, which is known to induce CD206 and arginase-1 expression, whereas SOCS-3 is essential for the development of M1 macrophages in vitro and in vivo. ${ }^{47}$ Functionally, the highly significant expression and up-regulation of CCL18 in the muscle tissue, which was identified as a central mediator of fibrosis in the affected muscle specimens from patients with sarcoidosis, has also been described in alveolar macrophages obtained by means of bronchoalveolar lavage from patients with idiopathic lung fibrosis. ${ }^{29}$

The agent driving the formation of giant cells in sarcoidosis and its functional relevance remain unclear, although the fundamental feature of granuloma formation on a "nidus of stimulating antigens" on the one hand and of the characteristic clinical course with special features in neurosarcoidosis on the other hand is underscored. ${ }^{10}$ In a more general approach, the molecular mechanisms of macrophage fusion have recently been intensely studied, ${ }^{27,48,49}$ and the link between an alternatively activated phenotype of macrophages and giant cell formation has been established. ${ }^{50}$ Furthermore, in parasitic infection with Schistosoma mansonii, giant cell formation depended on the presence of $\mathrm{IL}-4,{ }^{51}$ and IL-4 is also required in foreign body giant cell formation. ${ }^{52}$ Giant cell and granuloma formations are striking morphologic hallmarks in patients with muscle sarcoidosis. We identified DAP12 as being significantly up-regulated, which further argues for its functional significance in the context of M2 macrophage polarization. We, therefore, hypothesize that the granuloma-inducing stimulus may procure a special milieu during muscle sarcoidosis, which causes sustained macrophage stimulation, leading to an alternatively activated (M2) phenotype.

In conclusion, analysis of a comprehensive set of Th1/ Th2 mediators and cytokines, which regulate M1/M2 polarization of macrophages, investigated in human muscle specimens of patients with sarcoidosis have identified a dominant Th2 response with expression of M2 markers on macrophages and giant cells. The chronic inflammatory evolution of the disease is accompanied by important fibrosis of the muscle tissue, which, consequently, leads to an adverse clinical outcome of the disease in affected patients.

\section{Acknowledgments}

We thank Alexandra Döser, Elisabeth Löster, and Petra Matylewski for their technical support.

\section{References}

1. Griffith DE, Aksamit T, Brown-Elliott BA, Catanzaro A, Daley C, Gordin F, Holland SM, Horsburgh R, Huitt G, lademarco MF, Iseman M, Olivier K, Ruoss S, von Reyn CF, Wallace RJ Jr, Winthrop K: An official ATS/IDSA statement: diagnosis, treatment, and prevention of nontuberculous mycobacterial diseases. Am J Respir Crit Care Med 2007, 175:367-416

2. Grunewald J, Eklund A: Role of $\mathrm{CD}^{+}{ }^{+} \mathrm{T}$ cells in sarcoidosis. Proc Am Thorac Soc 2007, 4:461-464

3. Morey SS: American Thoracic Society issues consensus statement on sarcoidosis. Am Fam Physician 2000, 61:553-554, 556

4. Parrish S, Turner JF: Diagnosis of sarcoidosis. Dis Mon 2009, 55:693-703

5. Lazarus A: Sarcoidosis: epidemiology, etiology, pathogenesis, and genetics. Dis Mon 2009, 55:649-660

6. Chen ES, Moller DR: Etiology of sarcoidosis. Clin Chest Med 2008 , 29:365-377, vii 
7. Agostini C, Adami F, Semenzato G: New pathogenetic insights into the sarcoid granuloma. Curr Opin Rheumatol 2000, 12:71-76

8. Semenzato G, Adami F, Maschio N, Agostini C: Immune mechanisms in interstitial lung diseases. Allergy 2000, 55:1103-1120

9. Ziegenhagen MW, Muller-Quernheim J: The cytokine network in sarcoidosis and its clinical relevance. J Intern Med 2003, 253:18-30

10. Moller DR: Potential etiologic agents in sarcoidosis. Proc Am Thorac Soc 2007, 4:465-468

11. Hiramatsu J, Kataoka M, Nakata Y, Okazaki K, Tada S, Tanimoto M, Eishi Y: Propionibacterium acnes DNA detected in bronchoalveolar lavage cells from patients with sarcoidosis. Sarcoidosis Vasc Diffuse Lung Dis 2003, 20:197-203

12. Iannuzzi MC, Rybicki BA, Teirstein AS: Sarcoidosis. N Engl J Med 2007, 357:2153-2165

13. Newman LS, Rose CS, Bresnitz EA, Rossman MD, Barnard J, Frederick $M$, Terrin ML, Weinberger SE, Moller DR, McLennan G, Hunninghake G, DePalo L, Baughman RP, Iannuzzi MC, Judson MA, Knatterud GL, Thompson BW, Teirstein AS, Yeager H, Jr, Johns CJ, Rabin DL, Rybicki BA, Cherniack R: A case control etiologic study of sarcoidosis: environmental and occupational risk factors. Am J Respir Crit Care Med 2004, 170:1324-1330

14. Faurie P, Broussolle C, Zoulim F, Trepo C, Seve P: Sarcoidosis and hepatitis C: clinical description of 11 cases. Eur J Gastroenterol Hepatol 2010, 22:967-972

15. Doyle MK, Berggren R, Magnus JH: Interferon-induced sarcoidosis. J Clin Rheumatol 2006, 12:241-248

16. Dasilva V, Breuil V, Chevallier P, Euller-Ziegler L: Relapse of severe sarcoidosis with an uncommon peritoneal location after TNF $\alpha$ blockade: efficacy of rituximab, report of a single case. Joint Bone Spine 2010, 77:82-83

17. Stjernberg N, Cajander S, Truedsson H, Uddenfeldt P: Muscle involvement in sarcoidosis. Acta Med Scand 1981, 209:213-216

18. Zissel G, Prasse A, Muller-Quernheim J: Sarcoidosis: immunopathogenetic concepts. Semin Respir Crit Care Med 2007, 28:3-14

19. Lumeng CN, Bodzin JL, Saltiel AR: Obesity induces a phenotypic switch in adipose tissue macrophage polarization. J Clin Invest 2007, 117:175-184

20. Martinez FO, Helming L, Gordon S: Alternative activation of macrophages: an immunologic functional perspective. Annu Rev Immunol 2009, 27:451-483

21. Mosser DM: The many faces of macrophage activation. J Leukoc Biol 2003, 73:209-212

22. Mylonas KJ, Nair MG, Prieto-Lafuente L, Paape D, Allen JE: Alternatively activated macrophages elicited by helminth infection can be reprogrammed to enable microbial killing. J Immunol 2009, 182:3084-3094

23. Cassol E, Cassetta L, Rizzi C, Alfano M, Poli G: M1 and M2a polarization of human monocyte-derived macrophages inhibits HIV-1 replication by distinct mechanisms. J Immunol 2009, 182:6237-6246

24. Stenzel W, Dahm J, Sanchez-Ruiz M, Miletic H, Hermann M, Courts C, Schwindt $\mathrm{H}$, Utermohlen $\mathrm{O}$, Schluter D, Deckert M: Regulation of the inflammatory response to Staphylococcus aureus-induced brain abscess by interleukin-10. J Neuropathol Exp Neurol 2005, 64:1046-1057

25. Livak KJ, Schmittgen TD: Analysis of relative gene expression data using real-time quantitative PCR and the 2(-Delta Delta C(T)) Method. Methods 2001, 25:402-408

26. Ruckerl D, Hessmann M, Yoshimoto T, Ehlers S, Holscher C: Alternatively activated macrophages express the IL-27 receptor $\alpha$ chain WSX-1. Immunobiology 2006, 211:427-436

27. Helming L, Tomasello E, Kyriakides TR, Martinez FO, Takai T, Gordon $\mathrm{S}$, Vivier E: Essential role of DAP12 signaling in macrophage programming into a fusion-competent state. Sci Signal 2008, 1:ra11

28. Kinjo Y, Kawakami K, Uezu K, Yara S, Miyagi K, Koguchi Y, Hoshino T, Okamoto M, Kawase Y, Yokota K, Yoshino K, Takeda K, Akira S, Saito A: Contribution of IL-18 to Th1 response and host defense against infection by Mycobacterium tuberculosis: a comparative study with IL-12p40. J Immunol 2002, 169:323-329

29. Prasse A, Pechkovsky DV, Toews GB, Jungraithmayr W, Kollert F, Goldmann T, Vollmer E, Muller-Quernheim J, Zissel G: A vicious circle of alveolar macrophages and fibroblasts perpetuates pulmonary fibrosis via CCL18. Am J Respir Crit Care Med 2006, 173:781-792

30. Moller DR, Forman JD, Liu MC, Noble PW, Greenlee BM, Vyas P, Holden DA, Forrester JM, Lazarus A, Wysocka M, Trinchieri G, Karp C: Enhanced expression of IL-12 associated with Th1 cytokine profiles in active pulmonary sarcoidosis. J Immunol 1996, 156:4952-4960
31. Robinson BW, McLemore TL, Crystal RG: Gamma interferon is spontaneously released by alveolar macrophages and lung T lymphocytes in patients with pulmonary sarcoidosis. J Clin Invest 1985, 75:1488-1495

32. Hunninghake GW, Costabel U, Ando M, Baughman R, Cordier JF, du Bois R, Eklund A, Kitaichi M, Lynch J, Rizzato G, Rose C, Selroos O, Semenzato G, Sharma OP: ATS/ERS/WASOG statement on sarcoidosis: American Thoracic Society/European Respiratory Society/World Association of Sarcoidosis and other Granulomatous Disorders. Sarcoidosis Vasc Diffuse Lung Dis 1999, 16:149-173

33. Baumer I, Zissel G, Schlaak M, Muller-Quernheim J: Th1/Th2 cell distribution in pulmonary sarcoidosis. Am J Respir Cell Mol Biol 1997, 16:171-177

34. Parronchi P, Mohapatra S, Sampognaro S, Giannarini L, Wahn U, Chong P, Mohapatra S, Maggi E, Renz H, Romagnani S: Effects of interferon- $\alpha$ on cytokine profile: T cell receptor repertoire and peptide reactivity of human allergen-specific T cells. Eur J Immunol 1996, 26:697-703

35. Hurst EA, Mauro T: Sarcoidosis associated with pegylated interferon $\alpha$ and ribavirin treatment for chronic hepatitis $\mathrm{C}$ : a case report and review of the literature. Arch Dermatol 2005, 141:865-868

36. Benali S, Boustiere C, Castellani P, Cesari C, Jullien M, Lecomte L, Lebars O, Lambot G, Loyer R, Masseboeuf A, Perrier H, Oules V, Bourliere M: [Sarcoidosis following pegylated interferon therapy: two cases]. French. Gastroenterol Clin Biol 2006, 30:615-619

37. Ramos-Casals M, Mana J, Nardi N, Brito-Zeron P, Xaubet A, Sanchez-Tapias JM, Cervera R, Font J: Sarcoidosis in patients with chronic hepatitis $\mathrm{C}$ virus infection: analysis of 68 cases. Medicine (Baltimore) 2005, 84:69-80

38. Goldberg HJ, Fiedler D, Webb A, Jagirdar J, Hoyumpa AM, Peters J: Sarcoidosis after treatment with interferon- $\alpha$ : a case series and review of the literature. Respir Med 2006, 100:2063-2068

39. Möllers M, Aries SP, Dromann D, Mascher B, Braun J, Dalhoff K Intracellular cytokine repertoire in different $T$ cell subsets from patients with sarcoidosis. Thorax 2001, 56:487-493

40. Hauber HP, Gholami D, Meyer A, Pforte A: Increased interleukin-13 expression in patients with sarcoidosis. Thorax 2003, 58:519-524

41. Zhu Z, Homer RJ, Wang Z, Chen Q, Geba GP, Wang J, Zhang Y, Elias JA: Pulmonary expression of interleukin-13 causes inflammation, mucus hypersecretion, subepithelial fibrosis, physiologic abnormalities, and eotaxin production. J Clin Invest 1999, 103:779-788

42. Gordon S, Taylor PR: Monocyte and macrophage heterogeneity. Nat Rev Immunol 2005, 5:953-964

43. Varin A, Gordon S: Alternative activation of macrophages: immune function and cellular biology. Immunobiology 2009, 214:630-641

44. Desguerre I, Mayer M, Leturcq F, Barbet JP, Gherardi RK, Christov C: Endomysial fibrosis in Duchenne muscular dystrophy: a marker of poor outcome associated with macrophage alternative activation. J Neuropathol Exp Neurol 2009, 68:762-773

45. Goerdt S, Politz O, Schledzewski K, Birk R, Gratchev A, Guillot P, Hakiy N, Klemke CD, Dippel E, Kodelja V, Orfanos CE: Alternative versus classical activation of macrophages. Pathobiology 1999, 67:222-226

46. Kodelja V, Muller C, Tenorio S, Schebesch C, Orfanos CE, Goerdt S: Differences in angiogenic potential of classically vs alternatively activated macrophages. Immunobiology 1997, 197:478-493

47. Liu Y, Stewart KN, Bishop E, Marek CJ, Kluth DC, Rees AJ, Wilson $\mathrm{HM}$ : Unique expression of suppressor of cytokine signaling 3 is essential for classical macrophage activation in rodents in vitro and in vivo. J Immunol 2008, 180:6270-6278

48. Helming L, Gordon S: The molecular basis of macrophage fusion. Immunobiology 2007, 212:785-793

49. Helming L, Gordon S: Molecular mediators of macrophage fusion. Trends Cell Biol 2009, 19:514-522

50. Helming L, Gordon S: Macrophage fusion induced by IL-4 alternative activation is a multistage process involving multiple target molecules. Eur J Immunol 2007, 37:33-42

51. Chensue SW, Terebuh PD, Warmington KS, Hershey SD, Evanoff HL, Kunkel SL, Higashi GI: Role of IL-4 and IFN- $\gamma$ in Schistosoma mansoni egg-induced hypersensitivity granuloma formation: orchestration, relative contribution, and relationship to macrophage function. J Immunol 1992, 148:900-906

52. Kao WJ, McNally AK, Hiltner A, Anderson JM: Role for interleukin-4 in foreign-body giant cell formation on a poly(etherurethane urea) in vivo. J Biomed Mater Res 1995, 29:1267-1275 